\title{
CHANGES IN SOIL ORGANIC CARBON AND ITS FRACTIONS AFTER 13 YEARS OF CONTINUOUS STRAW RETURN IN A SOYBEAN-MAIZE CROPPING SYSTEM
}

\author{
HAO, X. X. ${ }^{1}-$ HAN, X. Z. ${ }^{1}-$ ZOU, W. X. ${ }^{1 *}-$ WANG, S. Y. ${ }^{1}-$ KWAW-MENSAH, D. ${ }^{2}$ \\ ${ }^{I}$ National Field Observation and Research Station of Hailun Agroecosystems, Key Laboratory \\ of Mollisols Agroecology, Northeast Institute of Geography and Agroecology, Chinese Academy \\ of Sciences, Harbin 150081, China \\ (phone: +86-451-866-01328; fax: +86-451-866-03736) \\ ${ }^{2}$ Department of Agronomy, Iowa State University, Ames, Iowa 50011, USA \\ (e-mail:dkwaw@iastate.edu) \\ ${ }^{*}$ Corresponding author \\ e-mail: zouwenxiu@iga.ac.cn; phone: +86-451-8669-1092; fax: +86-451-866-03736
}

(Received $6^{\text {th }}$ Aug 2020; accepted 22 $2^{\text {nd }}$ Oct 2020)

\begin{abstract}
Straw return to the soil is proposed as an effective practice to increase soil organic carbon (SOC) storage in croplands. Based on a 13-year field experiment with soybean-maize cropping system, we studied the changes of total SOC and SOC fractions under no fertilizer (NF), mineral fertilizers (NPK) and mineral fertilizers with straw return (NPKS). Compared with the initial soil, SOC storage in the bulk soil significantly increased by $7.19 \%$ in the NPKS treatment, with an annual increase of $0.32 \mathrm{Mg} \mathrm{ha}^{-1}$; while the SOC storage significantly decreased by $3.47 \%$ in the NF treatment, and no significant change was recorded in NPK treatment after 13 years. The NPKS treatment significantly increased the storage of free light fraction carbon (fLFC), occluded light fraction carbon (oLFC), heavy fraction (HFC), humic acid carbon (HAC) and fulvic acid carbon (FAC) by 44.4, 31.8, 5.4710 .5 and 3.92\%, respectively. The HAC contributed the highest percentage $(47.0 \%)$ of carbon to the improvement of SOC after 13 years of straw return. Therefore, straw return was conducive to the accumulation of labile fractions (fLFC and oLFC) which were in favor of soil fertility. Simultaneously, the increased HAC after straw return are beneficial to carbon sequestration.

Keywords: labile fraction carbons, Mollisol, soil density fractionation, long term fertilization, soil organic carbon storage
\end{abstract}

\section{Introduction}

Soil organic carbon (SOC) is an important pool in the global carbon (C) cycle, and has the function of mitigating climate change (Stockmann et al., 2013). Elevated levels of SOC have been positively related to crop productivity by enhancing soil fertility and plant nutrient supply (Lal, 2010; Singh et al., 2020). Therefore, management strategies that increase the net SOC of agricultural soils are considered soil health improvement strategies and promoted worldwide (Oliveira et al., 2019). However, this requires implementing agricultural practices adapted to local conditions that will increase the net soil $\mathrm{C}$ input, with outputs remaining stable or increasing, thus maximizing the soil $\mathrm{C}$ storage. In recent times, the impact of agricultural management on SOC storage has attracted much attention (Poeplau and Don, 2015; Chenu et al., 2019).

Crop straw return to the soil has been regarded as an environmentally friendly approach for straw utilization due to its positive effect on SOC storage in croplands (Liu et al., 2014), and widely adopted in diverse cropping systems. A number of studies have demonstrated that the duration of straw return to the soil has linearly increased SOC word wide in agroecosystem (Zhang et al., 2017; Jian et al., 2020). However, some studies have 
also reported a slight or no increase in SOC storage in response to crop straw return (Niu et al., 2011; Guo et al., 2015; Poeplau and Don, 2015). These differences might occur due to the duration of experiment. Jian et al. (2020) have reported that SOC could be significantly increased under the treatment experiencing straw return of more than 10 years, which depends on climate conditions, soil types, and agronomic practices. A metaanalysis has demonstrated that SOC could reach saturation under continuous straw return after 12 years (Liu et al., 2014). Therefore, medium- to long-term experiments are necessary to explore the dynamics of SOC under continuous straw return in agroecosystem.

SOC is heterogeneous and composed of several functional pools with different stability, which results in their turnover rates ranging from a few months to hundreds of years (von Lützow et al., 2007). To estimate the changes in SOC, it is crucial to quantify and understand the sensitivity of the different functional SOC pools to agricultural practices, for example straw return (Poeplau and Don, 2013). In view of SOC stabilization mechanisms, SOC can be separated to the following fractions: (1) unprotected fractions; (2) physically protected fractions by soil aggregates; (3) chemically or biochemically protected (Six et al., 2002; Yang et al., 2018). Various physical and chemical fractionation methods have been developed to separate SOC fractions with distinct degradability and turnover times. Density fractionation method highlights the observation that the physical location of SOC within the soil matrix is a key factor determining its turnover (Llorente et al., 2010). The obtained fractions are free light fraction (FLF), occluded light fraction within aggregates (OLF) and heavy fraction (HF). The FLF and OLF representing labile SOC pools with a rapid turnover time are both sensitive indicator of agronomic practices (Golchin et al., 1994; Tamn et al., 2005; Llorente et al., 2010). In contrast, HF is considered as stable pool, with turnover times ranging from decades to centuries. Generally, crop straw return has a positive effect on soil light fraction C (Nayak et al., 2012; Chen et al., 2019). The HF could be further chemically fractionated into three humic fractions (humic acid, fulvic acid and humin). Humic substances are operationally defined by a standardized extraction procedure, but previous studies have demonstrated that they are a heterogeneous pool of substances with distinct turnover rate (von Lützow et al., 2007). Crop straw is one of the major sources of humic substances in cropland soil (Guimarães et al., 2013). Several studies have addressed the effect of straw return on the size and composition of different humic fractions (Zhang et al., 2017, 2019a; Mi et al., 2019). Zhang et al. (2017) observed that continuous maize straw return increased humic and fulvic acid C concentrations in Mollisol. However, Mi et al. (2019) found that application of rice straw increased the concentrations of humic acid $\mathrm{C}$ only. Despite the widely researched response of different SOC fractions to straw return, the relative contributions of various functional SOC fractions to SOC change related to long-term straw return are still unclear.

Mollisols are one of the most important soil resources for food production and climate change mitigation due to their high organic C (Liu et al., 2012; Sanford et al., 2012). However, the SOC content of Mollisols has decreased rapidly over the past decades in the Northeast China, which is caused by long-term intensive cultivation and lower crop residue return (Li et al., 2016; Xu et al., 2020). In recent times, returning crop straw into soil is encouraged and widely applied in Northeast China aimed at improving soil fertility instead of burning the straw in the field (Wang et al., 2018). Previous studies have reported, that straw return could improve $\mathrm{C}$ sequestration by physically protecting soil macroaggregates and the occluded microaggregates (Guan et al., 2019), and also increase 
the soil recalcitrant $\mathrm{C}$ content (Zhang et al., 2019b). However, those studies were mainly conducted in continuous maize cropping systems in the south of the Mollisol region in Northeast China. Soybean-maize rotation is the primary cropping system in the north of the Mollisol region of China. Yet, a detailed examination of the changes in SOC and its fractions after straw return has not been considered in this region. The objectives of this study were to 1) identify the changes in SOC in the bulk soil and various fractions (light fractions, heavy fraction and humic fractions) after 13 years of continuing straw return under soybean-maize rotation, 2) assess the relative contributions of different SOC fractions to SOC change in relation to continue straw return. We hypothesize that continuous straw return would increase SOC storage both in the bulk soil and its fractions. Alternatively, the rate of increase of different SOC fractions caused by straw return would be different.

\section{Materials and Methods}

\section{Site description}

The field experiment was located at the National Field Observation and Research Station of Hailun Agroecosystems, Chinese Academy of Sciences (472 $\left.27^{\prime} \mathrm{N}, 126^{\circ} 55^{\prime} \mathrm{E}\right)$, in the central region of Mollisol in northeast China (Fig. 1). The region has a typical temperate continental monsoon climate with an average annual temperature of $1.5^{\circ} \mathrm{C}$. The lowest mean monthly temperature is $-23^{\circ} \mathrm{C}$ in January and the highest monthly mean temperature is $21^{\circ} \mathrm{C}$ in July. The mean annual precipitation of the region is $550 \mathrm{~mm}$, with more than $80 \%$ occurred from May to September. The frost-free period of the region is about 120 days. The soil of the study area is classified as Mollisol according to the USDA Soil Taxonomy System (Soil Survey Staff, 2010), which developed from sedimentary materials of loamy loess. The study site is a flat plain and had been under native prairie before the land was reclaimed for cropping about 120 years ago (Song et al., 2007). Before 1993, the cropping system was inter-annual rotation between wheat (Triticum aestivum L.) and soybean (Glycine $\max$ (L.) Merrill.), and between wheat, maize (Zea mays L.) and soybean rotation in 1993-2003.

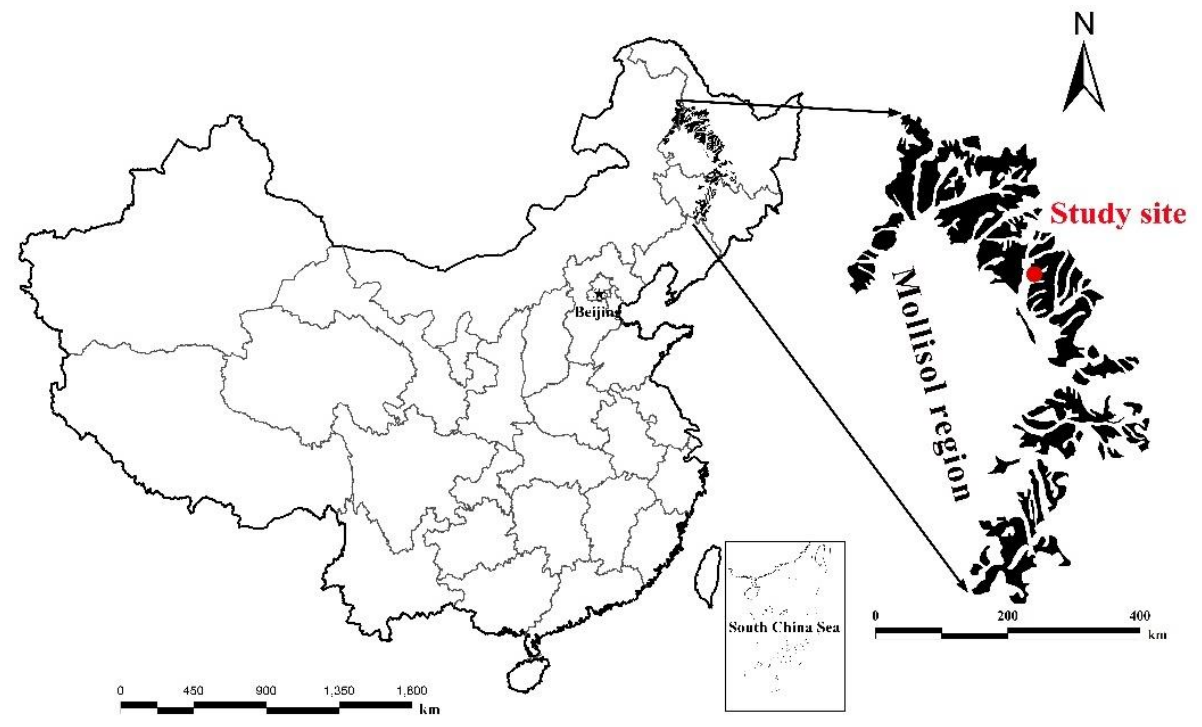

Figure 1. Geographical distribution of study site in northeast China 


\section{Experimental design}

The long-term experiment was established in 2004. The cropping system was interannual rotation between soybean and maize. Before 2004, all crop residues were removed from the field after harvest. Three treatments were set up in 2004, including no fertilizer (NF), mineral fertilizers (NPK) and mineral fertilizers with straw return (NPKS). The area of each treatment was $1800 \mathrm{~m}^{2}$ (width $30 \mathrm{~m} \times$ length $60 \mathrm{~m}$ ). Our experimental design was pseudo-replicated for NF, NPK and NPKS treatments, from which six composite soil samples were collected from each treatment. Our specific interest was assessing the SOC and SOC fractions in site-specific soil that had been treated for 13 years, representing the long-term agronomic outcomes. We presumed that any significant difference among those plots could be attributed to the effects of long-term treatment based on the random selection and low spatial variability of the soil characteristics. In the NF and NPK treatments, all aboveground straw was removed after harvest. In the NPKS treatment, maize or soybean straw was chopped to 3-4 cm in length after harvest, spread evenly in the treatment plot. All maize or soybean straws were plowed into the topsoil $(0-20 \mathrm{~cm}$ depth) by rotary tillage. In the NPK and NPKS treatments, the mineral fertilizers were applied at rates of $64 \mathrm{~kg} \mathrm{~N}$ $\mathrm{ha}^{-1}, 70 \mathrm{~kg} \mathrm{P}_{2} \mathrm{O}_{5} \mathrm{ha}^{-1}$ and $20 \mathrm{~kg} \mathrm{~K}_{2} \mathrm{O} \mathrm{ha}^{-1}$ for soybean, and $138 \mathrm{~kg} \mathrm{~N} \mathrm{ha}^{-1}, 70 \mathrm{~kg} \mathrm{P}_{2} \mathrm{O}_{5} \mathrm{ha}^{-1}$ and $20 \mathrm{~kg} \mathrm{~K}_{2} \mathrm{O} \mathrm{ha}^{-1}$ for maize. For the soybean, the mineral fertilizers were applied once as basal fertilizer at sowing. For maize, $\mathrm{P}$ and $\mathrm{K}$ fertilizers, and one third (33\%) of the $\mathrm{N}$ fertilizer were applied as basal fertilizer at sowing, and the remainder two thirds $(67 \%)$ was applied as topdressing at jointing stage. Mineral fertilizers were applied as urea $(46 \% \mathrm{~N})$, ammonium hydrogen phosphate $\left(18 \% \mathrm{~N} ; 46 \% \mathrm{P}_{2} \mathrm{O}_{5}\right)$ and potassium sulphate $\left(51 \% \mathrm{~K}_{2} \mathrm{O}\right)$. In all treatments, soils were subjected to conventional tillage, and were ridged by rotary tillage to a depth of $20 \mathrm{~cm}$ after harvest in autumn.

\section{Plant-derived C input estimates}

Every year, maize and soybean grain were manually harvest from five randomly selected sub-plots $\left(6 \mathrm{~m}^{2}\right)$ of each treatment plot to estimate grain yield at crop maturity. Organic matter derived from crop straw, roots, stubble and rhizodeposition in this study, was estimated by the average ratios of crop yields to the above residues from 2004 to 2017. The ratios were estimated by harvesting 10 individual plants of soybean and maize in September every year. Each plant was separated into grain, straw, stubble and root (0-20 cm soil depth), and oven-dried at $60{ }^{\circ} \mathrm{C}$ to constant weight and weighed to estimate the dry matter mass. The $\mathrm{C}$ concentration of each tissues was determined using a $\mathrm{CN}$ elemental analyzer (EA3000, Euro Vector, Italy). The average ratios of grain to straw, grain to stubble and grain to root were 1:0.73, 1:0.05 and 1:0.14 for soybean, respectively, and were 1:1.2, 1:0.13 and 1:0.26 for maize, respectively during experimental years. The $\mathrm{C}$ input derived from rhizodeposition was assumed to be equal to root biomass $\mathrm{C}$ (Bolinder et al., 1999).

\section{Soil sampling}

Soil samples were collected from the NF, NPK and NPKS treatments after harvest in each experimental year. Thirty randomized soil cores (depth 0-20 cm and diameter $5 \mathrm{~cm}$ ) were collected in each plot and every five soil cores were mixed as six composite soil samples. After removing visible plant fragments and roots, the fresh soil samples were sieved to pass through a $10-\mathrm{mm}$ sieve by gently breaking soil clods along the natural failure surfaces of the soil, air-dried, and then stored in glass bottles. A portion of the air- 
dried soils was ground to pass through a 2-mm sieve for analyses of SOC and its fractions. During soil sampling, five randomized point were selected at each sampling plot for the determination of soil bulk density. At each point, four soil cores $\left(100 \mathrm{~cm}^{3}\right)$ were sampled, and soil bulk density was measured after drying the soil cores at $105^{\circ} \mathrm{C}$ for $48 \mathrm{~h}$.

\section{SOC fractions analysis}

\section{Soil density fractionation}

Density fractionation of SOC was carried out following Llorente et al. (2010). $10 \mathrm{~g}$ air-dried soil sample $(<2 \mathrm{~mm})$ was placed in a $100 \mathrm{~mL}$ centrifuge tube with $50 \mathrm{~mL}$ sodium iodide (NaI) solution $\left(\mathrm{d}=1.8 \mathrm{~g} \mathrm{~cm}^{-3}\right)$. The tube was gently turned upside down 5 times by hand. After centrifugation for 30 minutes $(\mathrm{min})$ at 4000 revolutions per minute (rpm), the supernatant was passed through a $0.45 \mu \mathrm{m}$ membrane filter into a millipore vacuum unit. The separation method was repeated three times. The soil particles on the membrane were collected, washed with deionized water and considered as the free light fraction (fLF, $\mathrm{d}<1.8 \mathrm{~g} \mathrm{~cm}^{-3}$ ). The residue remaining in the tube was then added with $50 \mathrm{~mL} \mathrm{NaI}$. The tube was placed in an ice bath and sonicated at $300 \mathrm{~J} \mathrm{ml}^{-1}$ for $15 \mathrm{~min}$ with a probe-type ultrasonic disintegrator. The floating material was the occluded light fraction (oLF, $\mathrm{d}<1.8 \mathrm{~g} \mathrm{~cm}^{-3}$ ) protected by soil aggregates, then recovered by centrifugation, filtered and washed in the same way as the fLF. The leftover soil in the centrifuge tube was washed with distilled water until the water became clear and used as the heavy fraction (HF, $\mathrm{d}>1.8 \mathrm{~g} \mathrm{~cm}^{-3}$ ). All fractions were dried at $50{ }^{\circ} \mathrm{C}$, weighed, ground in a mortar, and analyzed for $\mathrm{C}$.

\section{Humic substance extraction}

The extraction of humic substance was preformed according to the method described by Stevenson (1994). Briefly, $50 \mathrm{~mL} 0.1 \mathrm{~mol} \mathrm{~L}^{-1} \mathrm{NaOH}$ and $0.1 \mathrm{~mol} \mathrm{~L}^{-1} \mathrm{Na}_{4} \mathrm{P}_{2} \mathrm{O}_{7}$ solution $(50: 50, \mathrm{v} / \mathrm{v})$ was added into the heavy fraction, and the tubes were then placed in a water bath at $70{ }^{\circ} \mathrm{C}$ for $1 \mathrm{~h}$. The supernatant solution was centrifuged at $3500 \mathrm{rpm}$ for $15 \mathrm{~min}$ and collected as the humic extractable substances (HE). The HE was acidified to $\mathrm{pH} 1.0$ with $0.5 \mathrm{~mol} \mathrm{~L}^{-1} \mathrm{H}_{2} \mathrm{SO}_{4}$, the precipitated fraction was acid-insoluble humic acid (HA), and the solution was fulvic acid (FA), the two fractions were separated by centrifugation at $3500 \mathrm{rpm}$ for $15 \mathrm{~min}$. The HA was re-dissolved by $0.05 \mathrm{~mol} \mathrm{~L}^{-1} \mathrm{NaOH}$. The residue soil was humin (HM) fraction. The C contents of HE (HEC) and HA (HAC) was determined by the $\mathrm{K}_{2} \mathrm{Cr}_{2} \mathrm{O}_{7}$ oxidation method. Carbon content of FA (FAC) and HM (HMC) were calculated using the following formulas:

$$
\begin{gathered}
\text { FAC }=\text { HEC }- \text { HAC } \\
\text { HMC }=\text { SOC }- \text { fLFC }- \text { oLFC }- \text { HEC }
\end{gathered}
$$

where, fLFC and oLFC are the C contents of fLF and oLF.

Total $\mathrm{C}$ contents in bulk soil and light fractions were determined using the CHN elemental analyzer (EA3000, Euro Vector, Italy).

\section{Statistical analysis}

Statistical analyses were performed by SPSS V19.0. One-way ANOVA with Tukey test was conducted to analyze the differences of SOC and SOC fractions among 
treatments at 5\% level of significance. Homogeneity of variance and normality assumption were tested using Levene's Test. The date differences between 2004 and 2017 were compared with paired t-test. Regression analysis was performed to determine the relationships between SOC content and experimental year.

\section{Results}

\section{Plant-derived C input}

During the 13-year experimental period, the cumulative C input in the NF, NPK and NPKS treatments were $10.92,15.12$ and $45.96 \mathrm{Mg} \mathrm{ha}^{-1}$, respectively (Table 1). In the NPKS treatment, the cumulative C input was $321 \%$ and $204 \%$ higher than NF and NPK, respectively, and $66.2 \%$ was derived from straw return, and more than $80 \%$ of cumulative $\mathrm{C}$ input were derived from root and rhizodeposition in the NF and NPK.

Table 1. Plant-derived C input in different treatments in 2004-2017 $\left(\mathrm{Mg} \mathrm{ha}^{-1}\right) . \mathrm{NF}$, No fertilizer; NPK, mineral fertilizers; NPKS, mineral fertilizers with straw return

\begin{tabular}{|c|c|c|c|c|c|c|c|c|c|}
\hline \multirow{2}{*}{ Treatment } & \multicolumn{2}{|c|}{ Straw $C^{\text {a }}$} & \multicolumn{2}{|c|}{ Root C } & \multicolumn{2}{|c|}{ Stubble C } & \multicolumn{2}{|c|}{ Rhizodeposition $\mathbf{C}^{\mathbf{b}}$} & \multirow{2}{*}{$\begin{array}{c}\text { Cumulative } \\
\mathrm{C} \text { input }\end{array}$} \\
\hline & Soybean & Maize & Soybean & Maize & Soybean & Maize & Soybean & Maize & \\
\hline $\mathrm{NF}$ & 0 & 0 & 0.88 & 3.52 & 0.31 & 1.81 & 0.88 & 3.52 & 10.92 \\
\hline NPK & 0 & 0 & 1.03 & 5.05 & 0.37 & 2.59 & 1.03 & 5.05 & 15.12 \\
\hline NPKS & 5.99 & 24.42 & 1.09 & 5.17 & 0.39 & 2.65 & 1.08 & 5.17 & 45.96 \\
\hline
\end{tabular}

${ }^{a}$ Soybean straw including the pod husk. ${ }^{\mathrm{b}}$ Carbon input from rhizodeposition was assumed to be equal to root biomass C (Bolinder et al., 1999)

\section{SOC storage in bulk soil}

Different agronomic practices had a significant impact on both SOC storage. After 13 years of different fertilizer treatments, significant differences in the storage of SOC were observed among treatments, shown as NPKS > NPK > NF (Fig. 2). Compared with the initial soil, the SOC storage significantly increased by $7.19 \%$ in the NPKS treatment $(P<0.05)$, with an annual average increase of $0.32 \mathrm{Mg} \mathrm{ha}^{-1}$. In the NF treatment, SOC storage significantly decreased by $3.47 \%$, and without any significant change in the NPK treatment over the past 13 years. The changes of SOC in the NPKS treatment, NPK and $\mathrm{NF}$ treatments were 4.10, 0.11 and $-2.02 \mathrm{Mg} \mathrm{ha}^{-1}$, respectively (Fig. 2).

\section{Temporal changes of SOC content}

Compared with the initial soil, SOC content in the NPKS treatment significantly increased $(P<0.001)$, and no significant changes $(P>0.05)$ in the NF and NPK treatments over the 13 years (Fig. 3). The SOC content in the NPKS treatment was significantly higher $(P<0.05)$ than those in the NF and NPK treatments in 2008 , four years after the experiment was established (2008). Subsequently, the significant differences among three treatments were recorded in the thirteenth year of the experiment with the highest SOC content in the NPKS treatment $\left(28.37 \mathrm{~g} \mathrm{~kg}^{-1}\right.$ soil), followed by the NPK treatment (26.35 $\mathrm{g} \mathrm{kg}^{-1}$ soil), and the lowest in the NF treatment $\left(25.16 \mathrm{~g} \mathrm{~kg}^{-1}\right.$ soil). Compared with the initial soil, SOC content increased by $19.5 \%$ for NPKS, but decreased 
by $6.64 \%$ for NF. It is worth noting that there were relatively high standard deviation values in the NPK treatment in 2013 and 2014, this might be caused by the variation of sample plots.

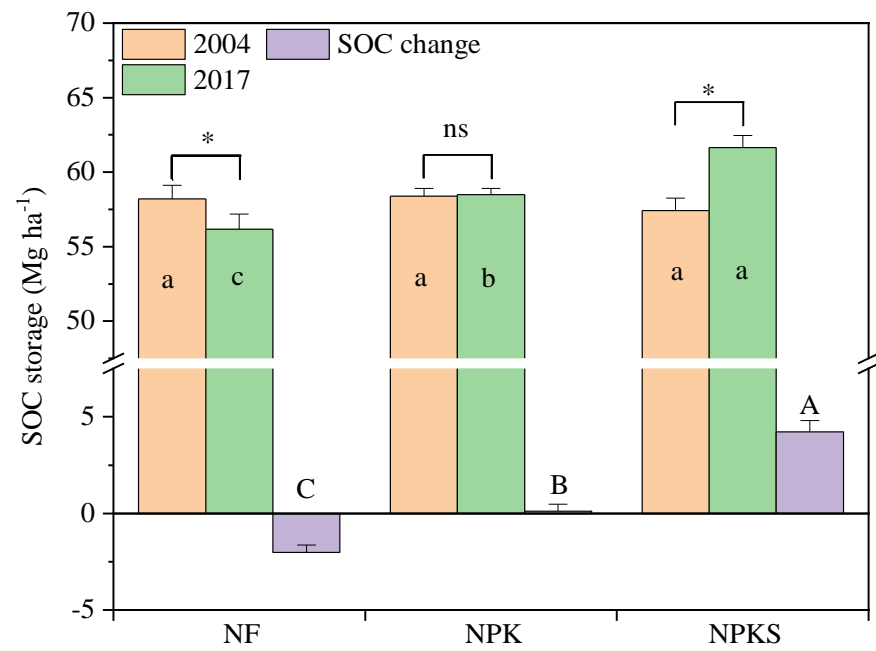

Figure 2. Soil organic carbon (SOC) storage change in bulk soils $(0-20 \mathrm{~cm})$ after 13 years of different treatments. NF, No fertilizer; NPK, mineral fertilizers; NPKS, mineral fertilizers with straw return. Different lowercase letters indicate significant differences $(P<0.05)$ in SOC storage among treatments in the same year. Different uppercase letters indicate significant

differences $(P<0.05)$ in SOC storage change among treatments. *Indicate significant differences $(P<0.01)$ between 2004 and 2017. Bars represent the standard deviations $(n=6)$

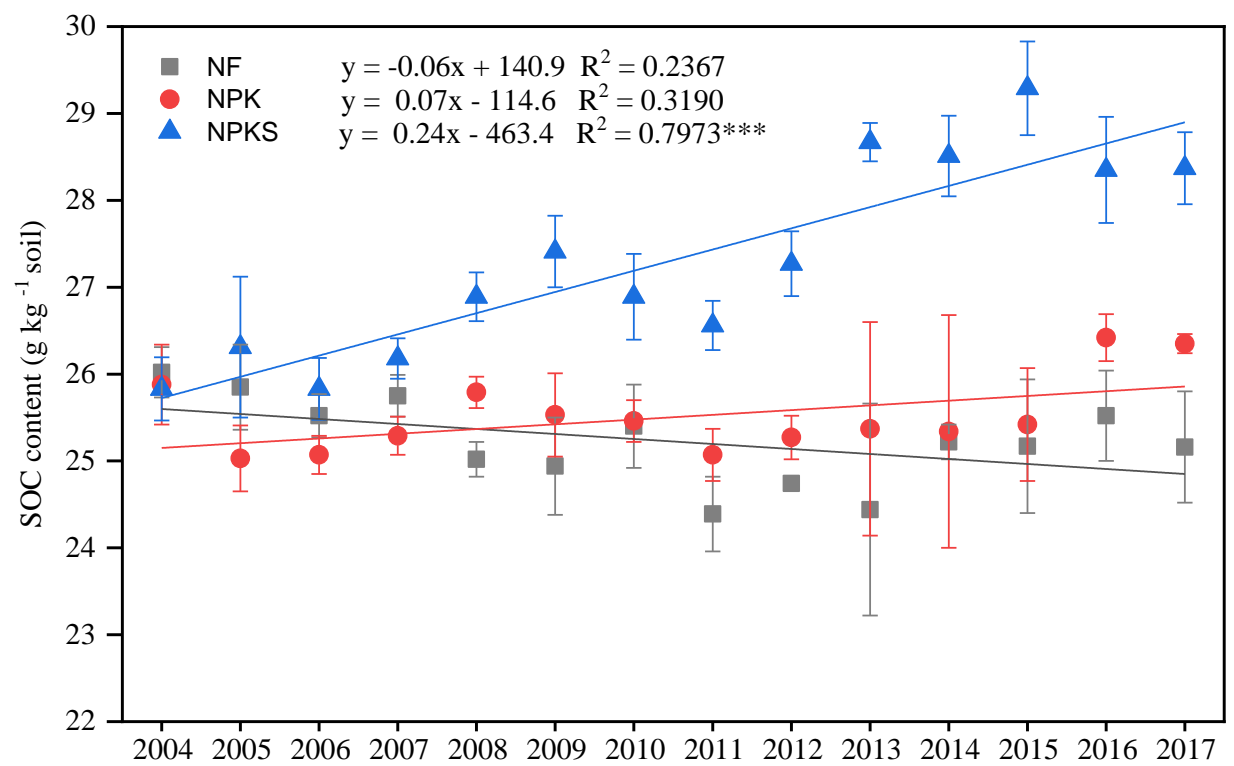

Figure 3. Changes in soil organic carbon $(S O C)$ content $(0-20 \mathrm{~cm})$ in different treatments during the period 2004-2017. NF, No fertilizer; NPK, mineral fertilizers; NPKS, mineral fertilizers with straw return. $* * *$ Indicate significance level at $P<0.001$. Bars represent the standard deviations $(n=6)$ 


\section{SOC storage in density and humic fractions}

Different agronomic practices have impacted the storage of SOC fractions in this study (Fig. 4). Compared with the initial SOC, treatment with continuous straw return with mineral fertilization significantly increased $(P<0.05)$ the storage of fLFC, oLFC, HFC, HAC and FAC by $44.4 \%, 31.8 \%, 5.47 \%, 10.5 \%$ and $3.92 \%$, respectively (Fig. $4 a, b, c$, $d, e)$. However, all of the above mentioned SOC fractions significantly decreased by $17.7 \%, 11.2 \%, 2.76 \%, 7.21 \%$ and $3.41 \%$ for fLFC, oLFC, HFC, HAC and FAC, respectively, under NF treatment. In the NPK treatment, there were no significant differences in all the SOC fractions between the soil samples taken in 2004 and 2017. After 13 years of experiment, the significant differences $(P<0.05)$ in the storage of fLFC, oLFC, HFC and HAC were recorded among the three treatments in the following order of NPKS > NPK > NF (Fig. $4 a, b, c, d$ ). However, there was no significant difference in the storage of HMC among three treatments (Fig. $4 f$ ).
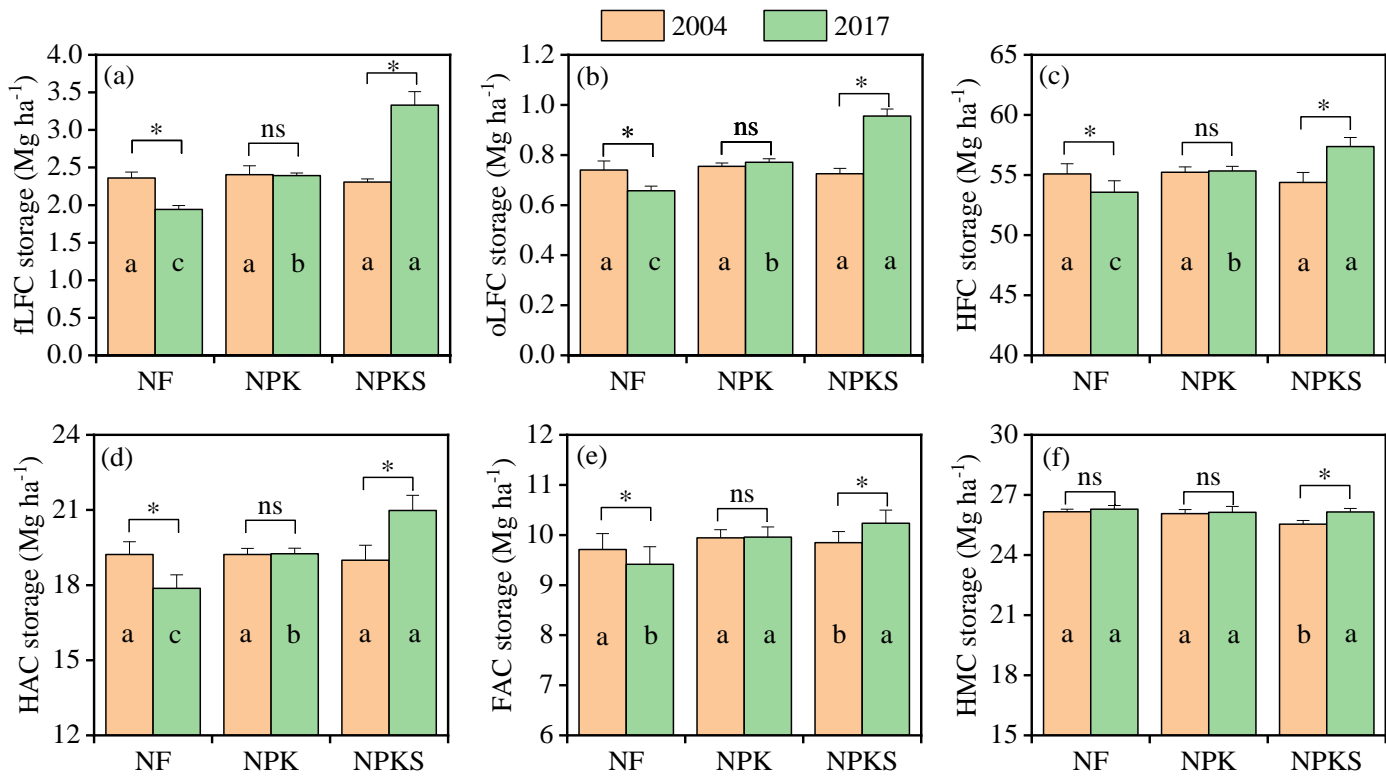

Figure 4. Carbon storage of soil organic carbon (SOC) fractions $(0-20 \mathrm{~cm})$ in different treatments in 2004 and 2017. NF, No fertilizer; NPK, mineral fertilizers; NPKS, mineral fertilizers with straw return. $\mathrm{fLFC}$, free light fraction carbon; oLFC, occluded light fraction carbon; HFC, heavy fraction carbon; HAC, humic acid carbon; FAC, fulvic acid carbon; HMC, humin carbon. Different lowercase letters indicate significant differences $(P<0.05)$ among treatments in the same year. * indicate significant differences $(P<0.01)$ between 2004 and 2017. Bars represent the standard deviations $(n=6)$

HMC, HAC, FAC, fLFC and oLFC storage accounted for 44.4\%-46.8\%, $33.1 \%-34.0 \%, 16.6 \%-17.2 \%, 3.46 \%-5.40 \%$ and $1.17 \%-1.55 \%$ of total SOC, respectively (Fig. 5). The NPKS treatment significantly increased $(P<0.05)$ the proportion of fLFC, oLFC and HAC by $34.5 \%, 22.7 \%$ and $2.88 \%$, respectively, but decreased the proportion of HMC by $4.66 \%$. The proportions of fLFC, oLFC and HAC under NF treatment were significantly decreased. Meanwhile, the different agronomic practices had a significant influence on the HA/FA ratio of humus, the largest value was recorded in the NPKS 
treatment with 2.05, followed by NPK treatment with 1.93 and NF treatment with 1.90 , NPKS of which were higher than the initial soil with 1.93 (Table 2).

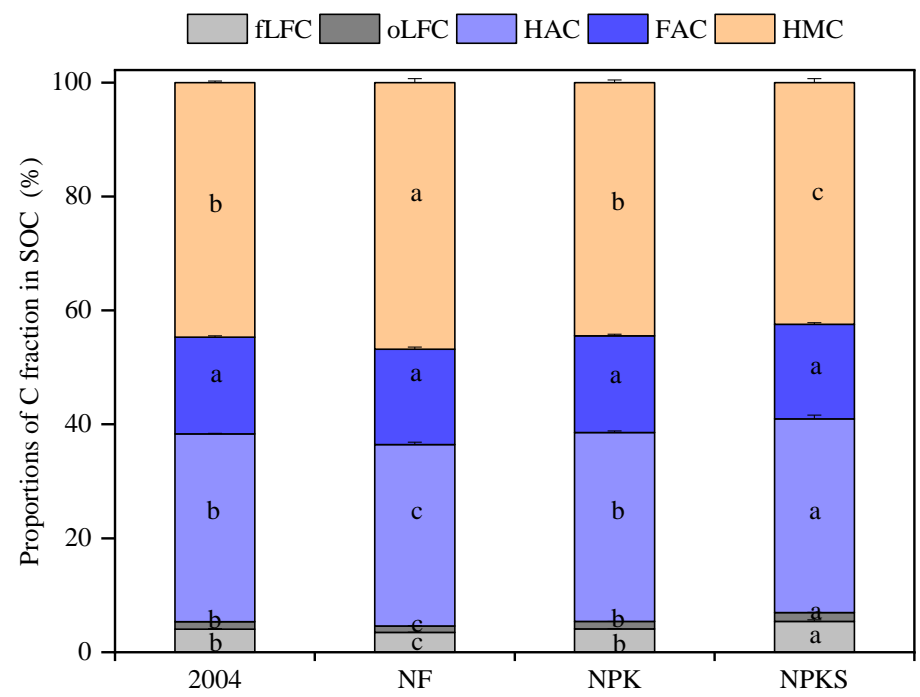

Figure 5. Proportion of carbon fractions in bulk soil organic carbon (SOC) $(0-20 \mathrm{~cm})$ in 2004 and 2017.The proportions of carbon fractions in 2004 are the mean value of the three treatments. NF, No fertilizer; NPK, mineral fertilizers; NPKS, mineral fertilizers with straw return. fLFC, free light fraction carbon; oLFC, occluded light fraction carbon; HFC, heavy fraction carbon; HAC, humic acid carbon; FAC, fulvic acid carbon; HMC, humin carbon. Different lowercase letters indicate significant differences $(P<0.05)$ among treatments. Bars represent the standard deviations $(n=6)$

Table 2. The HA/FA ratio of humus in different treatments in 2004 and 2017

\begin{tabular}{c|c|c}
\hline Treatment & $\mathbf{2 0 0 4}$ & $\mathbf{2 0 0 7}$ \\
\hline NF & $1.98 \pm 0.03 \mathrm{Aa}$ & $1.90 \pm 0.04 \mathrm{Bb}$ \\
NPK & $1.93 \pm 0.03 \mathrm{Ab}$ & $1.93 \pm 0.04 \mathrm{Ab}$ \\
NPKS & $1.93 \pm 0.03 \mathrm{Bb}$ & $2.05 \pm 0.02 \mathrm{Aa}$ \\
\hline
\end{tabular}

NF, No fertilizer; NPK, mineral fertilizers; NPKS, mineral fertilizers with straw return. Different lowercase letters indicate significant differences $(P<0.05)$ among treatments in the same year. Different uppercase letters indicate significant differences $(P<0.05)$ between 2004 and 2017 . The results are shown as the mean $\pm \mathrm{SD}(\mathrm{n}=6)$

\section{Contribution of C fractions on the improvement of SOC after straw return}

The increased amount of SOC fractions under NPKS treatment shown as the order of $\mathrm{HAC}>\mathrm{fLFC}>\mathrm{HMC}>\mathrm{FAC}>\mathrm{OLFC}$ (Table 3), and HAC accounting for $47.0 \%$ of SOC change was significantly higher than the other SOC fractions. Although the light fraction $\mathrm{C}$ accounted for only about $5 \%$ of SOC (Fig. 5), its contribution to the improvement of SOC was as higher as $29.8 \%$, including the increase of $24.3 \%$ from fLFC and $5.5 \%$ from oLFC, respectively (Table 3). However, the contribution of HMC to the improvement of SOC in the NPKS treatment was only $14.3 \%$, even though the HM accounted for more than $40 \%$ of SOC. 
Table 3. The change amount and the percentage contribution of different organic carbon fraction in $S O C(0-20 \mathrm{~cm})$. NF, No fertilizer; NPK, mineral fertilizers; NPKS, mineral fertilizers with straw return

\begin{tabular}{c|c|c|c|c|c|c}
\hline \multirow{2}{*}{ C fraction } & \multicolumn{3}{|c|}{ Change of C fractions $\left(\mathbf{M g ~ h a}^{-\mathbf{1}}\right)$} & \multicolumn{3}{c}{ Proportion to SOC change (\%) } \\
\cline { 2 - 7 } & NF & NPK & NPKS & NF & NPK & NPKS \\
\hline SOC & -2.02 & 0.11 & 4.23 & - & - & - \\
fLF & -0.42 & 0.00 & 1.02 & 21.1 & -29.9 & 24.3 \\
oLF & -0.08 & 0.02 & 0.23 & 4.2 & -11.3 & 5.5 \\
HA & -1.35 & 0.12 & 1.99 & 66.4 & 45.7 & 47.0 \\
FA & -0.29 & 0.06 & 0.39 & 15.1 & -63.8 & 9.0 \\
HM & 0.13 & 0.19 & 0.60 & -6.9 & 159.3 & 14.3 \\
\hline
\end{tabular}

SOC, soil organic carbon; NF, No fertilizer; NPK, mineral fertilizers; NPKS, mineral fertilizers with straw return; fLFC, free light fraction carbon; oLFC, occluded light fraction carbon; HFC, heavy fraction carbon; HAC, humic acid carbon; FAC, fulvic acid carbon; HMC, humin carbon

\section{Discussion}

\section{Change in bulk SOC in response to continuous straw return}

Our results clearly support the hypothesis that straw return to the soil has a positive impact on SOC storage and sequestration. SOC storage increased by $7.19 \%$ after 13 years of straw return to soil, with an annual increase of $0.32 \mathrm{Mg} \mathrm{ha}^{-1}$ in this study (Fig. 2). This increase in SOC was within the range presented by Zhang et al. (2010), who found that the rate of SOC sequestration ranged from 0.07 to $1.46 \mathrm{Mg} \mathrm{ha}^{-1}$ year $^{-1}$ under different upland cropping systems across northern China. Similarly, Wang et al. (2018) also reported a SOC sequestration rate of $0.28 \mathrm{Mg} \mathrm{ha}^{-1} \mathrm{yr}^{-1}$ in a 21-year straw return experiment in the same pedoclimatic region as this study. Generally, a significantly linear relationship occurs between straw $\mathrm{C}$ input and SOC sequestration rate when the soils do not reach the C-saturated point (Kong et al., 2005; Duval et al., 2016; Jiang et al., 2017). The average $\mathrm{C}$ input was $3.5 \mathrm{Mg} \mathrm{ha}^{-1} \mathrm{yr}^{-1}$ under NPKS treatment in this study (Table 1), which was $318 \%$ and $206 \%$ higher than the NF and NPK treatments. Consequently, the highest storage of SOC was found under NPKS treatment after 13 years (Fig. 2).

A meta-analysis has demonstrated that the effects of straw return on SOC content were not evident in short-term field experiments (1-3 years), but significantly increased in medium-term experiments (3-15 years). SOC contents showed a significantly increasing trend with the duration increase of straw return (Liu et al., 2014), which was consistent as our result. Although a significantly linear relationship between SOC content and experimental years of continuous straw return was found (Fig. 3), there was no significant change of SOC content in the first 3 years of straw return, which could be attributed to the relatively lower input of straw return under the soybean-maize rotation system. Different with our results, Liu et al. (2019) reported that the maize monoculture had continuously increased SOC content during the 8-year field experiment with straw return. The response of SOC to organic matter input depends on the initial SOC content (Chenu et al., 2019). When the initial SOC content is high, it is difficult to measure the change of SOC within a shorter period of time (Campbell et al., 1991). Berhane et al. (2020) has also described that soils with lower initial SOC have a higher potential to store and sequester SOC than soils with higher initial SOC following combined application of 
chemical fertilizer and straw. At the same study site, You et al. (2017) studied SOC changes during the early stages of the development of Mollisol with excessively low SOC $\left(4.79 \mathrm{~g} \mathrm{~kg}^{-1}\right.$ soil), and demonstrated that the return of maize and soybean straw induced a steady increase in SOC storage in the early years of the experiment with an annual SOC sequestration of $0.80 \mathrm{Mg} \mathrm{C} \mathrm{ha-1}$, which was relatively higher than that in this study $\left(0.32 \mathrm{Mg} \mathrm{ha}^{-1}\right)$ (Fig. 3). In addition, the effect of straw return on SOC accumulation was affected by straw return approaches and climate (Liu et al., 2014; Han et al., 2020; Jian et al., 2020). In general, crushing and incorporating straw into soil increased SOC more than mulching straw on soil surface (Han et al., 2020). Straw incorporation by tillage increases the contact between soil and straw, and thus promotes more straw $\mathrm{C}$ was sequestrated by soil. The decomposition rate of crop residue in this study area is substantially lower than other areas due to the low temperature in northeast of China $(\mathrm{Xu}$ et al., 2017). Therefore, incorporating straw in to the plough layer is an effective approach to accelerate the decomposition of straw in northeast of China (Han et al., 2020).

It has been widely accepted that SOC content could not be growing constantly with $\mathrm{C}$ input because of the potential upper limit of SOC concentration called the SOC saturation point, where there is an equilibrium between the $\mathrm{C}$ inputs and outputs (Stewart et al., 2007). Prior research has reported that due to the high base status of SOC, Mollisols can appear C saturation after many years of organic material input (Chung et al., 2010). In this study, a significantly linear relationship was found between SOC content and experimental years under the treatment with straw return (Fig. 3), which is an indication that the tested Mollisol has not reached an upper threshold of $C$ sequestration over the experimental period. This could be explained by the high clay content of Mollisols (>40\%) that could enhance the capacity of soil to store more C (Ding et al., 2012). However, we cannot conclude from this study that SOC saturation will occur with increasing straw-C inputs. Therefore, further long-term research is needed in this region to establish that conclusion of SOC saturation.

The above-ground biomass under the NF and NPK treatments was removed from filed and more than $80 \%$ of $\mathrm{C}$ input was derived from root (root biomass and rhizodeposition) in this study. Moreover, the root-derived $\mathrm{C}$ input is relatively lower under the $\mathrm{NF}$ treatment. Consequently, the cumulative $\mathrm{C}$ input was significantly lower in $\mathrm{NF}$ as compared with the NPK and NPKS treatments (Table 1), which contributed lower SOC storage under NF treatment (Fig. 2). Similar results have been reported in different climate and soil conditions (Lee et al., 2009; Ding et al., 2014; Yang et al., 2018). Applying mineral fertilizer alone for 13 years did not change SOC concentration and storage (Figs. 2, 3), indicating the SOC was in equilibrium and the input of $\mathrm{C}$ could compensate for the decomposition of SOC. The result from a 35-year field trial demonstrated that SOC would maintain the balance under the treatment with annual $\mathrm{C}$ input of $1.4 \mathrm{Mg} \mathrm{ha}^{-1}$ in northeast China (Hao et al., 2016), which is very close to the value under NPK treatment of our study. However, some studies showed that application of mineral fertilizer alone decreased SOC in Northeast China (Yan et al., 2007; Wang et al., 2013; Li et al., 2016). This reduction in SOC from the application of mineral fertilizer alone, could be attributed, in part, to the serious soil erosion in this area from slopes in fields due to hills in the landscape (Liu et al., 2010). The slope at this study site, is less than $2^{\circ}$ and the effects of soil erosion can be ignored. In this case, incorporating crop stubble and root biomass into soils consequently can compensate for the loss from the SOC mineralization. Including legumes in crop rotations has been introduced as a sustainable alternative to nitrogen fertilizer-based systems, due to the increased $\mathrm{N}$ 
availability to following crops, particularly when residues are added to the soil (Oliveira et al., 2019). In addition, legume crops have a positive effect on soil biology, promote the stabilization of soil aggregates, which protect native SOC from microbial decomposition, leading to increased soil C storage (Franke et al., 2018). Hence, rotation system including soybean is an effective practice to maintain the level of SOC in Mollisols.

\section{Effect of straw return on SOC density fractions}

Light fractions of SOC, mainly consisted of fresh plant-derived materials, represented labile SOC pools with rapid turnover rates (Golchin et al., 1994; Tamn et al., 2005; Llorente et al., 2010). In general, the light fractions of SOC is closely associated with soil nutrient cycling and soil fertility owing its impacts on soil food webs (Chen et al., 2017). The combined application of straw return and mineral fertilizer significantly increased not only the storage of fLFC and oLFC but also both proportion in SOC (Figs. 4, 5), which could be attributed to large straw inputs provided abundant source for the formation of light fractions under NPKS treatment. Moreover, the increase rate in light fraction $\mathrm{C}$ (44.4\% for fLFC, and $31.8 \%$ for oLFC) was much higher than that in bulk SOC (7.19\%), indicating that the light fraction $\mathrm{C}$ was more sensitive to straw return than bulk SOC. Previous studies have also reported that straw return significantly increased the light fraction C compared to no straw return (Nayak et al., 2012; Chen et al., 2017; Guan et al., 2019; Yan et al., 2020). After plant residue was incorporated into soil, part of residue directly existed in the soil as unprotected fLF, and part was protected by aggregates, which then slowly decomposed and utilized by soil microorganisms (Six et al., 2002). Although the light fraction C accounted for only $5 \%$ of SOC (Fig. 5), its contribution to the improvement of SOC was as high as $29.8 \%$ after 13 years of experiment with straw return to soil, including the increase of $24.3 \%$ from fLFC and 5.5\% from oLFC, respectively (Table 2). Similar result was reported by Yan et al. (2020), who found that more than $34 \%$ of the gain in SOC storage was stored in light fractions. Thus, light fraction $\mathrm{C}$ may be of greater importance in defining SOC turnover. Previous studies have indicated that the decrease of root biomass caused by the changes of soil management were the main factor that induced the decrease of light fraction C (Angst et al., 2018). In addition, higher amounts of root residue and exudates could promote the formation of soil aggregate, and thereby increase the oLFC that was physically protected within aggregates (Yamashita et al., 2006). Root-derived C in no fertilizer treatment was obviously lower than that in the fertilizer treatment (Table 1), which resulted in a significant decline of light fraction $\mathrm{C}$ in NF treatment compared with the initial soil (Fig. 4a, b).

The heavy fraction (HF) organic $\mathrm{C}$ is mineral associated fractions with a slower turnover rate and a higher degree of chemical protection (Llorente et al., 2010). More than $90 \%$ of organic C in Mollisol was stored in HF (Fig. 5). Although the storage of HFC increased by $5.47 \%$ after 13 years with continues straw return, it accounts for more than $70 \%$ of all increased SOC in the bulk soil. Likewise, Liu et al. (2008) found that the contribution rate of HFC to SOC improvement was $70.7 \%$ in the treatment with maize straw return in a 10-year experiment in Northeast China. This indicates that a larger proportion of the SOC storage derived from external C inputs was sequestered in HFC pool. Therefore, the response of HFC to soil management was slow, but it played a crucial role in maintaining the stability and quantity of SOC (Llorente et al., 2010). 


\section{Effect of straw return on SOC humic fractions}

In order to clarify the stable characteristics of SOM, we further fractionated HF to different humic fractions (i.e. HA, FA and HM). The $\mathrm{C}$ storage in humic substances were characterized as $\mathrm{HM}>\mathrm{HA}>\mathrm{FA}$ (Fig. $4 d$, e, f), which is consistent with published results in Mollisol (Zhang et al., 2019a). Crop residue is one of the major sources of humic substances in farmland soil (Guimarães et al., 2013). Hence all of the three humic fractions were significantly increased by continuous straw return to soil. Humic-like substances in organic amendments have been documented to contribute to the accumulation of native soil humic substances (Brunetti et al., 2007). Crop straw contained a certain amount of humic-like substances (Adani and Ricca, 2004). During the straw decomposition process, this humic-like substance could be adsorbed by soil minerals (Simonetti et al., 2012), meanwhile, some released labile biomolecules (e.g., polysaccharides, peptides and aliphatic compounds) could be incorporated into native soil humic substances throw chemical protection. When the soil was in a net loss of SOC, its humic fractions was always in a decreasing state (Guimarães et al., 2013). Therefore, the treatment with no mineral fertilization significantly decreased the $\mathrm{C}$ storage in HA and FA (Fig. $4 d, e$ ). On the other hand, mineral fertilizers alone did not significantly affect the $\mathrm{C}$ storage in humic fractions (Fig. $4 d, e, f$ ), which implies that the humic composition of Moillsol is always in a stable state under the conventional management.

The ratio of HA/FA could provide information on the humification rate and accumulation regularity of SOC under different management (Guimarães et al., 2013). The HA/FA ratio significantly increased after 13 years of combined application of straw return and mineral fertilizers compared with initial soil, mineral fertilizers alone and no fertilizers in this study, indicating that long-term straw application was more conducive to the accumulation of HAC. This could be further proved by the highest contribution rates of HAC (47\%) to the SOC improvement (Table 3). Previous studies conducted in Fluvisol (Shindo et al., 2006), Inceptisol (Zhang et al., 2011) and Hapludoll (Song et al., 2019) also reported that application of straw or organic manure in combination with mineral fertilizers could increase the HA/FA ratio of SOM. A plausible explanation is that FA was more soluble and reactive than HA (Dou et al., 2020). In the early stage of crop residues decomposition, the formation of FA fractions is rapid, however, the FA later would be easily transferred into more stable HA fractions under microbe's activity (Ingelmo et al., 2012; Dou et al., 2020). Thus, our result suggested that medium-term application of straw is favorable for the formation of HA fraction. The HA fraction would play a major "sink" role in the process of SOC sequestration.

\section{Conclusions}

A 13-year field experiment demonstrates that, due to the higher $\mathrm{C}$ input by straw, the combined application of straw return and mineral fertilizer significantly increased SOC in the top 0-20 cm layer of a Mollisol under soybean-maize cropping system. There was a positive linear relationship between SOC content and increasing years with straw return, which indicates that Mollisols do not reach saturation point in $\mathrm{C}$ sequestration over the experimental period. The storage of organic $\mathrm{C}$ in density (i.e. fLF, fLF and HF) and humic fractions (i.e. HA, FA and HM) were also generally higher after the returning of straw. Moreover, straw return clearly increased the proportion of fLFC, oLFC and HAC, but decreased the proportion of HMC, resulting in the HA/FA ratios being higher than the application of no fertilizer and mineral fertilizers. The HA fractions contributed the 
highest rates to the SOC improvement after 13 years straw return. The storage of SOC and its fractions did not change under treatment with application of mineral fertilizers alone, indicated an equilibrium state of SOC. It was concluded that SOC fractions in response to straw return were different. In addition, this study was only over a mediumterm period of 13 years, a long-term study is needed to verify the effects of crop straw return on SOC fractions in a soybean-maize rotation system in Northeast China.

Acknowledgements. This research was funded by the National Key Research and Development Program of China (2016YFD0200309), the National Natural Science Foundation of China (41807094, 41771327, 41807085), China Agriculture Research System (CARS-04), applied Technology Research and Development Program of Heilongjiang (GY2017ZB006).

\section{REFERENCES}

[1] Adani, F., Ricca, G. (2004): The contribution of alkali soluble (humic acid-like) and unhydrolyzed-alkali soluble (core-humic acid-like) fractions extracted from maize plant to the formation of soil humic acid. - Chemosphere 56: 13-22.

[2] Angst, G., Messinger, J., Greiner, M., Häusler, W., Hertel, D., Kirfel, K., Kögel-Knabner, I., Leuschner, C., Rethemeyer, J., Mueller, C. W. (2018): Soil organic carbon stocks in topsoil and subsoil controlled by parent material, carbon input in the rhizosphere, and microbial-derived compounds. - Soil Biology and Biochemistry 122: 19-30.

[3] Berhane, M., Xu, M., Liang, Z., Shi, J., Wei, G., Tian, X. (2020): Effects of long-term straw return on soil organic carbon storage and sequestration rate in North China upland crops: A meta-analysis. - Global Change Biology 26: 2686-2701.

[4] Bolinder, M. A., Angers, D. A., Giroux, M., Laverdière, M. R. (1999): Estimating C inputs retained as soil organic matter from corn (Zea Mays L.). - Plant and Soil 215: 85-91.

[5] Brunetti, G., Plaza, C., Clapp, C. E., Senesi, N. (2007): Compositional and functional features of humic acids from organic amendments and amended soils in Minnesota, USA. - Soil Biology and Biochemistry 39: 1355-1365.

[6] Campbell, C. A., Bowren, K. E., Schnitzer, M., Zentner, R. P., Townleysmith, L. (1991): Effect of crop rotations and fertilization on soil organic matter and some biochemical properties of a thick Black Chernozem. - Canadian Journal of Soil Science 71: 377-387.

[7] Chen, Z. M., Wang, H. Y., Liu, X. W., Zhao, X. L., Lu, D. J., Zhou, J. M., Li, C. Z. (2017): Changes in soil microbial community and organic carbon fractions under short-term straw return in a rice-wheat cropping system. - Soil and Tillage Research 165: 121-127.

[8] Chen, S. C., Arrouays, D., Angers, D. A., Martin, M. P., Walter, C. (2019): Soil carbon stocks under different land uses and the applicability of the soil carbon saturation concept. - Soil and Tillage Research 188: 53-58.

[9] Chenu, C., Angers, D. A., Barré, P., Derrien, D., Arrouays, D., Balesdent, J. (2019): Increasing organic stocks in agricultural soils: Knowledge gaps and potential innovations. - Soil and Tillage Research 188: 41-52.

[10] Chung, H., Ngo, K. J., Plante, A., Six, J. (2010): Evidence for carbon saturation in a highly structured and organic-matter-rich soil. - Soil Science Society of America Journal 74(1): 130-138.

[11] Ding, X. L., Han, X. Z., Liang, Y., Qiao, Y. F., Li, L. J., Li, N. (2012): Changes in soil organic carbon pools after 10 years of continuous manuring combined with chemical fertilizer in a Mollisol in China. - Soil and Tillage Research 122: 36-41.

[12] Ding, X. L., Yuan, Y. R., Liang, Y., Li, L. J., Han, X. Z. (2014): Impact of long-term application of manure, crop residue, and mineral fertilizer on organic carbon pools and crop yields in a Mollisol. - Journal of Soils and Sediments 14: 854-859. 
[13] Dou, S., Shan, J., Song, X. Y., Cao, R., Wu, M., Li, C. L., Guan, S. (2020): Are humic substances soil microbial residues or unique synthesized compounds? A perspective on their distinctiveness. - Pedosphere 30: 159-167.

[14] Duval, M. E., Galantini, J. A., Capurro, J. E., Martinez, J. M. (2016): Winter cover crops in soybean monoculture: Effects on soil organic carbon and its fractions. - Soil and Tillage Research 161: 95-105.

[15] Franke, A. C., van den Brand, G. J., Vanlauwe, B., Giller, K. E. (2018): Sustainable intensification through rotations with grain legumes in Sub-Saharan Africa: A review. Agriculture, Ecosystems and Environment 261: 172-185.

[16] Golchin, A., Oades, J. M., Skjemstad, J. O., Clarke, P. (1994): Study of free and occluded particulate organic matter in soils by solid state ${ }^{13} \mathrm{C}$ Cp/MAS NMR spectroscopy and scanning electron microscopy. - Soil Research 32: 285-309.

[17] Guan, S., Liu, S. J., Liu, R. Y., Zhang, J. J., Ren, J., Cai, H. G., Lin, X. X. (2019): Soil organic carbon associated with aggregate-size and density fractions in a Mollisol amended with charred and uncharred maize straw. - Journal of Integrative Agriculture 18: 14961507.

[18] Guimarães, D. V., Gonzaga, M. I. S., da Silva, T. O., da Silva, T. L., da Silva Dias, N., Matias, M. I. S. (2013): Soil organic matter pools and carbon fractions in soil under different land uses. - Soil and Tillage Research 126: 177-182.

[19] Guo, L. J., Zhang, Z. S., Wang, D. D., Li, C. F., Cao, C. G. (2015): Effects of short-term conservation management practices on soil organic carbon fractions and microbial community composition under a rice-wheat rotation system. - Biology and Fertility of Soils 51: 65-75.

[20] Han, Y., Yao, S. H., Jiang, H., Ge, X. L., Zhang, Y. L., Mao, J. D., Dou, S., Zhang, B. (2020): Effects of mixing maize straw with soil and placement depths on decomposition rates and products at two cold sites in the Mollisol region of China. - Soil and Tillage Research 197: 104519.

[21] Hao, X. Y., Ma, X. Z., Zhou, B. K., Li, Y. D. (2016): Effect of different long-term fertilization practices on carbon sequestration in black soil. - Journal of Soil and Water Conservation 30: 316-321. (In Chinese).

[22] Ingelmo, F., Molina, M. J., Soriano, M. D., Gallardo, A., Lapeña, L. (2012): Influence of organic matter transformations on the bioavailability of heavy metals in a sludge based compost. - Journal of Environmental Management 95: S104-S109.

[23] Jian, J. S., Du, X., Reiter, M. S., Stewart, R. D. (2020): A meta-analysis of global cropland soil carbon changes due to cover cropping. - Soil Biology and Biochemistry 143: 107735.

[24] Jiang, C. M., Yu, W. T., Ma, Q., Xu, Y. G., Zou, H. (2017): Alleviating global warming potential by soil carbon sequestration: A multi-level straw incorporation experiment from a maize cropping system in Northeast China. - Soil and Tillage Research 170: 77-84.

[25] Kong, A. Y. Y., Six, J., Bryant, D. C., Denison, R. F., Kessel, C. V. (2005): The relationship between carbon input, aggregation, and soil organic carbon stabilization in sustainable cropping systems. - Soil Science Society of America Journal 69: 1078.

[26] Lal, R. (2010): Managing soils and ecosystems for mitigating anthropogenic carbon emissions and advancing global food security. - Bioscience 60: 708-721.

[27] Lee, S. B., Lee, C. H., Jung, K. Y., Park, K. D., Lee, D., Kim, P. J. (2009): Changes of soil organic carbon and its fractions in relation to soil physical properties in a long-term fertilized paddy. - Soil and Tillage Research 104: 227-232.

[28] Li, L. J., Burger, M., Du, S. L., Zou, W. X., You, M. Y., Hao, X. X., Lu, X. C., Lin, Z., Han, X. Z. (2016): Change in soil organic carbon between 1981 and 2011 in croplands of Heilongjiang Province, northeast China. - Journal of the Science of Food and Agriculture 96: $1275-1283$.

[29] Liu, S. X., Wang, Y., Zhou, P., Zhao, L. P., Liu, J. S., Qin, Z. J. (2008): Effect of various fertilization on the organo-mineral complexation and the combined forms of humus of phaeozem. - Journal of Nanjing Agricultural University 31: 76-80. (In Chinese). 
[30] Liu, X. B., Lee Burras, C., Kravchenko, Y. S., Duran, A., Huffman, T., Morras, H., Studdert, G., Zhang, X. Y., Cruse, R. M., Yuan, X. H. (2010): Soil degradation: A problem threatening the sustainable development of agriculture in Northeast China. - Plant Soil and Environment 56: 87-97.

[31] Liu, X. B., Zhang, X. Y., Wang, Y. X., Sui, Y. Y., Ding, G. (2012): Overview of Mollisols in the world: Distribution, land use and management. - Canadian Journal of Soil Science 92: 383-402.

[32] Liu, C., Lu, M., Cui, J., Li, B., Fang, C. M. (2014): Effects of straw carbon input on carbon dynamics in agricultural soils: a meta-analysis. - Global Change Biology 20: 1366-1381.

[33] Liu, X., Zhou, F., Hu, G. Q., Shao, S., He, H. B., Zhang, W., Zhang, X. D., Li, L. J. (2019): Dynamic contribution of microbial residues to soil organic matter accumulation influenced by maize straw mulching. - Geoderma 333: 35-42.

[34] Llorente, M., Glaser, B., Turrión, M. B. (2010): Storage of organic carbon and Black carbon in density fractions of calcareous soils under different land uses. - Geoderma 159: 31-38.

[35] Mi, W. H., Sun, Y., Gao, Q., Liu, M. Y., Wu, L. H. (2019): Changes in humus carbon fractions in paddy soil given different organic amendments and mineral fertilizers. - Soil and Tillage Research 195: 104421.

[36] Nayak, A. K., Gangwar, B., Shukla, A. K., Mazumdar, S. P., Kumar, A., Raja, R., Kumar, A., Kumar, V., Rai, P. K., Mohan, U. (2012): Long-term effect of different integrated nutrient management on soil organic carbon and its fractions and sustainability of ricewheat system in Indo Gangetic Plains of India. - Field Crops Research 127: 129-139.

[37] Niu, L. A., Hao, J. M., Zhang, B. Z., Niu, X. S. (2011): Influences of long-term fertilizer and tillage management on soil fertility of the North China Plain. - Pedosphere 21: 813820.

[38] Oliveira, M., Barré, P., Trindade, H., Virto, I. (2019): Different efficiencies of grain legumes in crop rotations to improve soil aggregation and organic carbon in the short-term in a sandy Cambisol. - Soil and Tillage Research 186: 23-35.

[39] Poeplau, C., Don, A. (2013): Sensitivity of soil organic carbon stocks and fractions to different land-use changes across Europe. - Geoderma 192: 189-201.

[40] Poeplau, C., Don, A. (2015): Carbon sequestration in agricultural soils via cultivation of cover crops - A meta-analysis. - Agriculture, Ecosystems and Environment 200: 33-41.

[41] Sanford, G. R., Posner, J. L., Jackson, R. D., Kucharik, C. J., Hedtcke, J. L., Lin, T. L. (2012): Soil carbon lost from Mollisols of the North Central U.S.A. with 20 years of agricultural best management practices. - Agriculture, Ecosystems and Environment 162: 68-76.

[42] Shindo, H., Hirahara, O., Yoshida, M., Yamamoto, A. (2006): Effect of continuous compost application on humus composition and nitrogen fertility of soils in a field subjected to double cropping. - Biology and Fertility of Soils 42: 437-442.

[43] Simonetti, G., Francioso, O., Nardi, S., Berti, A., Brugnoli, E., Francesco Morari, E. L. (2012): Characterization of humic carbon in soil aggregates in a long-term experiment with manure and mineral fertilization. - Soil Science Society of America Journal 76: 880.

[44] Singh, S., Nouri, A., Singh, S., Anapalli, S., Lee, J., Arelli, P., Jagadamma, S. (2020): Soil organic carbon and aggregation in response to thirty-nine years of tillage management in the southeastern US. - Soil and Tillage Research 197: 104523.

[45] Six, J., Conant, R. T., Paul, E. A., Paustian, K. (2002): Stabilization mechanisms of soil organic matter: Implications for C-saturation of soils. - Plant and Soil 241: 155-176.

[46] Soil Survey Staff (2010): Keys to Soil Taxonomy. - United States Department of Agriculture, Natural Resources Conservation Service, Washington, DC.

[47] Song, C., Han, X. Z., Tang, C. (2007): Changes in phosphorus fractions, sorption and release in Udic Mollisols under different ecosystems. - Biology and Fertility of Soils 44: $37-47$. 
[48] Song, X. Y., Li, Y., Yue, X., Hussain, Q., Zhang, J. J., Liu, Q. H., Jin, S. A., Cui, D. J. (2019): Effect of cotton straw-derived materials on native soil organic carbon. - Science of the Total Environment 663: 38-44.

[49] Stevenson, F. J. (1994): Humus chemistry: Genesis, composition reactions, 2nd ed. - John Wiley and Sons, New York: 496p.

[50] Stewart, C. E., Paustian, K., Conant, R. T., Plante, A. F., Six, J. (2007): Soil carbon saturation: concept, evidence and evaluation. - Biogeochemistry 86: 19-31.

[51] Stockmann, U., Adams, M. A., Crawford, J. W., Field, D. J., Henakaarchchi, N., Jenkins, M., Minasny, B., McBratney, A. B., de Courcelles, V. d. R., Singh, K., Wheeler, I., Abbott, L., Angers, D. A., Baldock, J., Bird, M., Brookes, P. C., Chenu, C., Jastrow, J. D., Lal, R., Lehmann, J., O’Donnell, A. G., Parton, W. J., Whitehead, D., Zimmermann, M. (2013): The knowns, known unknowns and unknowns of sequestration of soil organic carbon. Agriculture, Ecosystems and Environment 164: 80-99.

[52] Tamn, Y., Heiner, F., John, B. (2005): Organic matter in density fractions of water-stable aggregates in silty soils: effect of land use. - Soil Biology and Biochemistry 38: 32223234.

[53] von Lützow, M., Kögel-Knabner, I., Ekschmitt, K., Flessa, H., Guggenberger, G., Matzner, E., Marschner, B. (2007): SOM fractionation methods: Relevance to functional pools and to stabilization mechanisms. - Soil Biology and Biochemistry 39: 2183-2207.

[54] Wang, G. C., Luo, Z. K., Wang, E. L., Huang, Y. (2013): Contrasting effects of agricultural management on soil organic carbon balance in different agricultural regions of China. Pedosphere 23: 717-728.

[55] Wang, S. C., Zhao, Y. W., Wang, J. Z., Zhu, P., Cui, X., Han, X. Z., Xu, M. G., Lu, C. A. (2018): The efficiency of long-term straw return to sequester organic carbon in Northeast China's cropland. - Journal of Integrative Agriculture 17: 436-448.

[56] Xu, Y. H., Chen, Z. M., Fontaine, S., Wang, W. J., Luo, J. F., Fan, J. L., Ding, W. X. (2017): Dominant effects of organic carbon chemistry on decomposition dynamics of crop residues in a Mollisol. - Soil Biology and Biochemistry 115: 221-232.

[57] Xu, X. R., Pei, J. B., Xu, Y. D., Wang, J. K. (2020): Soil organic carbon depletion in global Mollisols regions and restoration by management practices: a review. - Journal of Soils and Sediments 20: 1173-1181.

[58] Yamashita, T., Flessa, H., John, B., Helfrich, M., Ludwig, B. (2006): Organic matter in density fractions of water-stable aggregates in silty soils: Effect of land use. - Soil Biology and Biochemistry 38: 3222-3234.

[59] Yan, H. M., Cao, M. K., Liu, J. Y., Tao, B. (2007): Potential and sustainability for carbon sequestration with improved soil management in agricultural soils of China. - Agriculture, Ecosystems and Environment 121: 325-335.

[60] Yan, S. S., Song, J. M., Fan, J., Yan, C., Dong, S. K., Ma, C. M., Gong, Z. P. (2020): Changes in soil organic carbon fractions and microbial community under rice straw return in Northeast China. - Global Ecology and Conservation 22: e00962.

[61] Yang, F., Tian, J., Meersmans, J., Fang, H. J., Yang, H., Lou, Y. L., Li, Z. F., Liu, K. L., Zhou, Y., Blagodatskaya, E., Kuzyakov, Y. (2018): Functional soil organic matter fractions in response to long-term fertilization in upland and paddy systems in South China. - Catena 162: 270-277.

[62] You, M. Y., Li, N., Zou, W. X., Han, X. Z., Burger, M. (2017): Increase in soil organic carbon in a Mollisol following simulated initial development from parent material. European Journal of Soil Science 68: 39-47.

[63] Zhang, W. J., Wang, X. J., Xu, M. G., Huang, S. M., Liu, H., Peng, C. (2010): Soil organic carbon dynamics under long-term fertilizations in arable land of northern China. Biogeosciences 7: 409-425.

[64] Zhang, J. J., Cao, Z. Y., Feng, G. Z., Li, M. Y., Li, C. L., Gao, Q., Wang, L. C. (2011): Effects of earthworm activity on humus composition and humic acid characteristics of soil 
in a maize residue amended rice-wheat rotation agroecosystem. - Applied Soil Ecology 51:1-8.

[65] Zhang, J. J., Hu, F., Li, H. X., Gao, Q., Song, X. Y., Ke, X. K., Wang, L. C. (2017): Effects of Integrated soil-crop system management on soil organic carbon characteristics in a Primosol in Northeast China. - Pedosphere 27: 957-967.

[66] Zhang, J. J., Wei, Y. X., Liu, J. Z., Yuan, J. C., Liang, Y., Ren, J., Cai, H. G. (2019a): Effects of maize straw and its biochar application on organic and humic carbon in waterstable aggregates of a Mollisol in Northeast China: A five-year field experiment. - Soil and Tillage Research 190: 1-9.

[67] Zhang, Y., Li, X. J., Gregorich, E. G., McLaughlin, N. B., Zhang, X. P., Guo, Y. F., Gao, Y., Liang, A. Z. (2019b): Evaluating storage and pool size of soil organic carbon in degraded soils: Tillage effects when crop residue is returned. - Soil and Tillage Research 192: 215-221. 